\title{
COEVOLUTION IN BACTERIAL-PLASMID POPULATIONS
}

\author{
Rajiv I. Modi ${ }^{1}$ AND JULIan Adams ${ }^{2}$ \\ Department of Biology, University of Michigan, Ann Arbor, MI 48109 USA
}

\begin{abstract}
Evolutionary changes are described in plasmid-containing strains isolated after approximately 800 generations of growth in glucose-limited chemostat culture. The reproductive fitness increased dramatically over this period. Genetic changes associated with the increases in fitness were localized to both the bacterial and the plasmid chromosomes. In addition, some of the genetic changes on the bacterial and the plasmid chromosomes interact to minimize the deleterious effect of the plasmid. Thus, the changes observed may be considered coevolutionary. Reductions in the deleterious effects of the plasmid were shown to be associated with a decrease in plasmid copy number and an increase in the rate of segregational loss of the plasmid.
\end{abstract}

Key words. - Coevolution, continuous culture, E. coli, plasmid.

Received June 6, 1990. Accepted September 27, 1990.

It is now well known that bacteria often possess extrachromosomal circular molecules of DNA, or plasmids. Such plasmids, which may range in size from a few kilobases $(\mathrm{kb})$ to hundreds of $\mathrm{kb}$ in size, may carry genes coding for a wide range of phenotypes, including resistances to antibiotics and heavy metals, the ability to metabolize exotic chemicals, as well as the ability to transmit themselves from one cell to another (conjugation). In a number of cases plasmids have been identified that endow the cell with no known phenotype (so-called cryptic plasmids). Plasmids, in contradistinction to their close relatives the bacteriophages, are unable to lead an independent existence outside of the bacterial cell. Thus, the evolutionary fates of plasmids are inseparably associated with those of their bacterial hosts.

In the absence of the appropriate selective agent, a number of studies have shown that antibiotic resistance plasmids, considered to be of recent origin (R-plasmids; Melling et al., 1977; Engberg and Nordstrom, 1975; Godwin and Slater, 1979; Zund and Lebek, 1980; Wouters and van Andel, 1979), as well as artifically constructed plasmids (Inselburg, 1978; Jones et al., 1980; Roth et al., 1980; Wouters et al., 1980; Helling et al., 1981; Noack et al., 1981; Lee and Edlin, 1985; Boe et al., 1987; Chiang and Bremer, 1988) have a strong negative effect on the

\footnotetext{
1 Present address: Cadila Laboratories, Ahmedabad, Gujurat-380008, Gujurat, India.

${ }^{2}$ To whom reprint requests should be addressed.
}

growth and reproduction of the host, though there are notable exceptions (Wouters and van Andel, 1979). Such plasmids may therefore be considered to be parasites of the host bacterial cells harboring them. Application of classic host/parasite theory to evolution in bacterial-plasmid populations allows a number of predictions to be made, as discussed extensively by Levin and Lenski (1983). Among the evolutionary changes expected in the two chromosomes are a reduction of the deleterious effect of the plasmid(s), which can result from independent or coordinated changes in both the bacterial and plasmid chromosomes. Thus, Bouma and Lenski (1988), analyzing the evolution of a bacteria/plasmid association, showed that changes in the bacterial chromosome had occurred to modify the initial deleterious effect of the plasmid into one that was beneficial. Of particular interest is the possibility that coevolutionary changes (Futuyma and Slatkin, 1983) may occur in the bacterial chromosome and the plasmid; that is, evolutionary changes occurring in the bacterial chromosome in response to the presence of the plasmid, and evolutionary changes occurring in the plasmid in response to the cell environment specified by the bacterial chromosome.

In this communication we analyze changes that have occurred in two different plasmidcontaining strains that were isolated after almost 800 generations of evolution in a glucose-limited environment (Helling et al., 1987). The population was inoculated with a single plasmid-containing clone. Shortly after generation 100, plasmid-free cells ap- 
peared in the population and increased in frequency rapidly. Until about generation 550 , the frequency of plasmid-containing cells fluctuated, at frequencies varying between 0.1 and 0.6 , until about generation 550. Thereafter, the frequency of plasmidcontaining cells decreased significantly, although fluctuations in their frequency were still apparent. At the termination of the experiment, at generation 773 , plasmid-containing cells constituted a small minority of the population. Similar fluctuations were observed by Helling et al. (1981) and were shown to be manifestations of adaptive genetic changes occurring in the bacterialplasmid sector of the population. The two plasmid-containing clones isolated exhibited different colony morphologies as well as physiological differences (Helling et al., 1987). We show that i) the deleterious effect of the plasmid has been reduced during evolution; ii) evolutionary changes in the plasmid are primarily responsible for an attenuation of its deleterious effect; and iii) evolutionary changes in the plasmid and the bacterial chromosomes interact to maximize fitness.

\section{MATERIALS AND METHODS}

Growth Media.-Tryptone broth (TB) contained $5 \mathrm{~g} \mathrm{NaCl}$ and $10 \mathrm{~g}$ tryptone (Difco) per liter. Tryptone agar (TA) was TB plus $1.4 \%(\mathrm{w} / \mathrm{v})$ agar. The minimal medium used was that of Davis and Mingioli (1950), lacking citrate and containing thiamine $\cdot \mathrm{HCl}$ at $1 \mu \mathrm{g} \mathrm{ml}^{-1}$. The carbon source in the form of $\mathrm{D}$-glucose was present at a concentration of $0.025 \% \mathrm{w} / \mathrm{v}$ in batch cultures and at $0.0125 \% \mathrm{w} / \mathrm{v}$ in chemostats. This latter concentration of D-glucose which resulted in glucose being the limiting substrate, maintained population densities of approximately $1 \times 10^{8}$ organisms $\mathrm{ml}^{-1}$ in chemostat culture. D-glucose (Sigma) and thiamine $\cdot \mathrm{HCl}$ (Sigma) were sterilized by filtration through $0.22 \mu \mathrm{m}$ pore-size nitrocellulose membrane (Millipore GS) prior to use in the chemostat medium. After autoclaving the medium, ampicillin was added, when necessary, to a concentration of $50 \mu \mathrm{g}$ $\mathrm{ml}^{-1}$ for solid or liquid medium.

Organisms and Plasmids.-Escherichia coli JA104 and its derivatives and plasmid pBR322 45 (Heffron et al., 1981) and its de- rivatives (Table 1) were used. Strains carrying the plasmid pBR322 $\Delta 5$ are resistant to both ampicillin and tetracycline. CV101 and CV103 were plasmid-containing ampicillin-resistant and tetracycline-resistant strains obtained from single colonies on TA plates after plating samples from the chemostat bacterial population that had been maintained for approximately 773 generations of growth in glucose-limited chemostat culture. Plasmid-containing strains were obtained by transformation with purified plasmid DNA using the standard $\mathrm{CaCl}_{2}$ procedure (Maniatis et al., 1982). The presence of a plasmid in strains recovered from chemostat cultures was demonstrated by extracting the plasmid DNA by the alkaline lysis method and resolving the restriction endonuclease digested DNA on agarose gels stained with ethidium bromide (Maniatis et al., 1982). Plasmid-free derivatives of JA122 and CV 101 were initially isolated by assaying colonies for $\beta$-lactamase using the iodometric assay described by Boyko and Ganschow (1982). Plasmid-free derivatives of CV103 were initially isolated by replicaplating onto TA + tetracycline plates, and identification of tetracycline-sensitive colonies. This was necessary as plasmid-free derivatives of CV103 still possess a low level of ampicillin resistance. Absence of the plasmid was confirmed by quantitative Southern analysis (Maniatis et al., 1982), probing with plasmid DNA, and analyzing the resulting autoradiographs with a laserscanning densitometer (LKB Ultroscan XL). Plasmid-free derivatives of CV103 contained below detectable levels of plasmid DNA $(<0.04$ plasmid copies/bacterial chromosome).

In the absence of an antibiotic resistance marker, an arabinose resistance marker was used to distinguish different strains in our assays of relative fitness. Arabinose-resistant derivatives were obtained by plating the appropriate strains on EMB (eosinmethylene blue) arabinose medium. L-Arabinose is toxic to strains containing the $\operatorname{araD} 139$ mutation. The arabinose nonutilizing but resistant mutants have second mutations in the ara $A$, ara $B$ or ara $C$ genes (Boyer et al., 1962). All strains were stored at $-70^{\circ} \mathrm{C}$ in $40 \%(\mathrm{w} / \mathrm{v})$ glycerol.

Procedure for Competition Experiments 
TABLE 1. Bacterial strains.

\begin{tabular}{llcc}
\hline \hline & & \multicolumn{2}{c}{$\begin{array}{c}\text { Replicon } \\
\text { designation }\end{array}$} \\
\cline { 2 - 4 } \multicolumn{1}{c}{ Strain } & \multicolumn{1}{c}{ Relevant characteristics } & E.li & Plasmid \\
\hline JA104 & F $^{-}$thi1 lacY1 araD 139 supE44 hss1 lysogenic for $\lambda$ (Adams et al., & $b_{0}$ \\
& 1979) & & \\
CV106 & As JA104 but arabinose resistant & $b_{0}$ & \\
JA122 & JA104 transformed with plasmid pBR32245 (Heffron et al., 1981); & $b_{0}$ & $p_{0}$ \\
original strain & ampicillin and tetracycline resistant & & \\
CV107 & As JA122 but arabinose resistant & $b_{0}$ & $p_{0}$ \\
JA234 & JA104 transformed with plasmid from CV101 & $b_{0}$ & $p_{1}$ \\
CV110 & As JA234 but arabinose resistant & $b_{0}$ & $p_{1}$ \\
JA233 & JA104 transformed with plasmid from CV103 & $b_{0}$ & $p_{2}$ \\
CV109 & As JA233 but arabinose resistant & $b_{0}$ & $p_{2}$ \\
RIM21 & Spontaneous plasmid-free segregant of CV101 & $b_{1}$ & \\
CV101 & Derivative of JA122-evolved strain isolated after approximately 773 & $b_{1}$ & $p_{1}$ \\
evolved strain 1 & generations of glucose-limited continuous culture (Helling et al., & & \\
& 1987); ampicillin and tetracycline resistant & & \\
CV105 & As CV101 but arabinose resistant & $b_{1}$ & $p_{1}$ \\
RIM212 & RIM21 transformed with plasmid from JA122 & $b_{1}$ & $p_{0}$ \\
JA238 & As RIM212 but arabinose resistant & $b_{1}$ & $p_{0}$ \\
RIM213 & RIM21 transformed with plasmid from CV103 & $b_{1}$ & $p_{2}$ \\
JA240 & As RIM212 but arabinose resistant & $b_{1}$ & $p_{2}$ \\
CV103 & As CV101 but independent isolate which forms small colonies (Hell- & $b_{2}$ & $p_{2}$ \\
evolved strain 2 & ing et al., 1987) & $b_{2}$ & \\
RIM10 & Spontaneous plasmid-free segregant of CV103; ampicillin resistant & $b_{2}$ & \\
\hline
\end{tabular}

in Continuous Culture. - Chemostat cultures were maintained at $30^{\circ} \mathrm{C}$ in a glucoselimited minimal salt chemostat medium (Helling et al., 1981) in aerated culture vessels $120-195 \mathrm{ml}$ in volume, at a constant dilution rate of $0.2 \mathrm{hr}^{-1}$, equivalent to a cell generation time of approximately 3.5 hours (Kubitschek, 1970). The bacterial population density was monitored by measuring the culture absorbance at $550 \mathrm{~nm}$ in a Bausch and Lomb Spectronic 100 spectrophotometer. Two strains were grown in batch mode for 14-18 hours, in a minimal medium containing glucose and supplemented with ampicillin (Sigma), when necessary. Typically, the competition experiments were initiated by inoculating the chemostat with an equal number of the two competing strains from the batch culture. To increase the time that data could be gathered, the initial frequencies for some competition experiments, such as between JA122 and CV103 where the fitness differences were large, were adjusted so that the superior strain was in the minority. Just before addition of the inoculum the outflow tube of the chemostat was clamped, the cultures were allowed to mix adequately, and the clamp was then removed. Data collection commenced when numerical equilibrium (as determined by culture absorbance at $\mathrm{A}_{550}$ ) was attained. All competition experiments were terminated after 20-25 generations to avoid complications due to the occurrence of faster growing adaptive mutants (Helling et al., 1987).

Changes in the frequencies of the two competing strains were monitored by plating samples at appropriate dilutions on TA plates and replicating these onto the appropriate selective plates (TA plus arabinose $[0.12 \%, w / v]$, TA plus ampicillin [50 $\mu \mathrm{g}$ $\mathrm{ml}^{-1}$ ], TA plus arabinose plus ampicillin plates, or TA plus tetracycline $\left.\left[10 \mu \mathrm{g} \mathrm{ml}^{-1}\right]\right)$. Typically 200 colonies were replicated for each sample. In many competition experiments colony size on TA provided an independent estimate of frequency. The frequency of $\operatorname{ara}^{\mathrm{R}}$ organisms in each sample was calculated as the ratio of the number of arabinose-resistant colonies to the total number of colonies replicated. Similarly, changes in the frequency of the plasmid were monitored by replicating the TA plates onto TA plus ampicillin or tetracycline. In experiments involving mixtures of plasmid containing arabinose-resistant and arabinose-sensitive strains, the frequency of arabinose-resistant organisms was estimated by also replicating the colonies appearing on TA onto TA plus arabinose and ampi- 
cillin and scoring growth after 8-10 hours at $37^{\circ} \mathrm{C}$. Thus, in all competition experiments involving plasmid-containing strains the frequencies of the two competing strains were corrected for the loss of plasmid. Experiments in which the frequency of the spontaneous plasmid-free derivatives increased above $6 \%$ of the total parent population were not considered in the data set. Control competition experiments were performed to estimate the selective effect of mutations to arabinose-resistance in glucose-limited chemostat culture. Under our conditions, the arabinose resistance phenotype exhibited a small selective disadvantage $(s=0.035 \pm 0.009)$. There was no evidence that the selective effect of the arabinose resistance phenotype was affected by the bacterial and plasmid genotypes in the competition experiments, described here. Relative fitnesses were corrected for the effect of the arabinose marker, where necessary. Each estimate of relative fitness is presented together with the standard error of the estimate and was obtained from a single competition experiment. For most pairs of strains, replicate competition experiments were carried out. We assume each experiment provides an unbiased, independent estimate of relative fitness.

The fitness of the strain predominating in the competition experiments is defined as unity. The selective coefficient of the less successful strain is defined as the absolute value of the slope of the least square regression of the change in the frequencies of the two strains over time (in cell generations) after linearization of the frequencies with a logit transformation. In all cases, the logit transformation resulted in an excellent fit of the data to the linear model, indicating no evidence for frequency-dependent selection. The number of cell generations was determined from $(D \times t) / \ln 2$, where $D$ is the dilution rate $\left(\mathrm{hr}^{-1}\right)$ and $t$ is the time (hr) since the beginning of the competition experiment (Kubitschek, 1970). The standard errors associated with the relative fitnesses must be regarded as approximate as the errors associated with the data points are unavoidably autocorrelated.

Occasionally, faster growing mutant derivatives of strain CV103, characterized by large colony morphology on tryptone agar
(TA) plates, appeared during growth in batch culture. Therefore, in all competition experiments involving strain CV103 and its derivatives, samples were plated at the end of batch growth on tryptone agar (TA) plates to test for the presence of revertants with a large colony morphology. Competition experiments initiated using such cultures were aborted and were not included in the data set.

Determination of Plasmid Copy Number.-Direct estimates of plasmid copy number were obtained from quantitative Southern analysis using the Schleicher and Schuell, Minifold II "slot-blotting" apparatus. For continuous cultures, cells were obtained directly from the chemostats that had attained numerical equilibrium growing at a dilution rate of $0.2 \mathrm{hr}^{-1}$. For batch cultures, cells in mid-log phase were used. Approximately $10^{7}$ cells grown in minimal medium at $30^{\circ} \mathrm{C}$ were pelleted in sterile tubes using a table-top micro-centrifuge (Fisher) for five minutes. The pellet was resuspended in $100 \mathrm{ml}$ of $10 \mathrm{mM}$ Tris $\cdot \mathrm{HCl}, \mathrm{pH} 7.0$. The cells were lysed by incubating the suspension at $55^{\circ} \mathrm{C}$ for 90 minutes with occasional gentle vortexing, in $100 \mathrm{ml}$ of lysis buffer, containing $0.05 \mathrm{M}$ Tris- $\mathrm{HCl}, 1.0 \%$ Triton $\mathrm{X}-100,1 \mathrm{mg} / \mathrm{ml}$ of lysozyme (Sigma), $1.0 \%$ proteinase $\mathrm{K}$ (Boehringer Mannheim Biochemicals), $\mathrm{pH}$ 8.0. The lysate was purified by two phenol/chloroform extractions. The aqueous layers from the two extractions were pooled, 0.1 volume (about $400 \mu \mathrm{l}$ ) of $3.0 \mathrm{M}$ $\mathrm{NaOH}$ added and incubated for $0.5 \mathrm{hr}$ at $65^{\circ} \mathrm{C}$ (to destroy RNA and denature the DNA), and then cooled to room temperature, and neutralized by adding 1.0 volume $2 \mathrm{M}$ ammonium acetate $(\mathrm{pH} 7.0)$. Various dilutions of the sample DNA, prepared as described above, were loaded on the Nytran (Schleicher and Schuell) membranes as suggested by the manufacturer. Pure DNA (as determined from the $A_{260} / A_{280}$ ratio), used as quantitative standards, was resuspended in $400 \mathrm{ml}$ of $10 \mathrm{mM}$ Tris $\cdot \mathrm{HCl}, \mathrm{pH} 7.0,1$ mM EDTA, and then the $\mathrm{NaOH}$ and ammonium acetate were added as described above. The amount of DNA was estimated from the absorbance at $260 \mathrm{~nm}$. Various dilutions of the DNA, used as internal standards for estimating the amount of DNA, prepared as described above, were loaded 
on the Nytran (Schleicher and Schuell) membrane containing the sample DNAs. The membranes were hybridized with probe DNA (pure plasmid DNA isolated from JA122, described earlier) labeled by nicktranslation with ${ }^{32} \mathbf{P}$ dCTP using the kit supplied by Boehringer Mannheim. The autoradiograms were scanned using the Ultroscan XL Laser densitometer and the amount of DNA homologous to plasmid DNA in various samples was determined. The plasmid copy number (number of plasmid copies per cell) was then calculated from $\hat{x} / \hat{y} \hat{z}$, where $\hat{x}$ is the estimated amount of plasmid DNA in the slot, as determined from the standards, $\hat{y}$ is the number of cells from which the plasmid DNA was obtained, and $\hat{z}$ is the amount of plasmid DNA/plasmid chromosome, estimated to be $9.862 \times$ $10^{-9} \mathrm{ng}$.

Indirect Estimation of Plasmid Copy Number. - Relative plasmid copy number of the strain was estimated indirectly from the levels of ampicillin required to limit growth. Plasmid-containing cells were used to inoculate TB medium containing ampicillin at a final concentration of $50 \mu \mathrm{g} / \mathrm{ml}$ and the culture was grown at $30^{\circ} \mathrm{C}$ overnight. The overnight culture was used to inoculate TB containing ampicillin at concentrations varying between 0 to $7 \mathrm{mg} / \mathrm{ml}$. A function, defined as,

$$
f\left(\mathrm{~A}_{550}\right)=\frac{\exp \{\alpha+\beta x\}}{1+\exp \{\alpha+\beta x\}}+\gamma
$$

where $x$ is the concentration of ampicillin $(\mathrm{mg} / \mathrm{ml}), \alpha$ and $\beta$ are parameters of the logistic equation, and $\gamma$ is a parameter representing displacement along the $x$ axis, was fitted to the absorbance values $\left(A_{550}\right)$ of the different cultures, after 16 hours of growth at $30^{\circ} \mathrm{C}$ in a roller drum (New Brunswick Scientific) in different ampicillin concentrations, using nonlinear regression employing numerical estimation of the partial derivative (Dixon et al., 1985). This equation was chosen as it gave an excellent fit to the data. The minimum inhibitory concentration for a strain is defined as the concentration of the antibiotic (ampicillin) that allows a maximum cell density of 0.15 absorbance units using the above growth conditions, as calculated from the least squares regression equation.
Determination of Plasmid Segregation Rate.-Segregation rate of the plasmid is defined here as the rate of loss of plasmid from the cell per cell per cell division. Thus, the change in the frequency of plasmid-containing cells is described by

$$
p_{t}=p_{0} e^{-v t} \approx p_{0}(1-v t),
$$

where $p_{0}$ is the frequency of plasmid-containing cells at time $0, p_{t}$ is the frequency of plasmid-containing cells at time $t$, and $v$ is the plasmid segregation rate. The ratio of the total cell density (cells $\mathrm{ml}^{-1}$ ) to the initial cell density was used to calculate the average number of generations during batch growth.

Plasmid-containing cells were used to inoculate minimal medium batch cultures as described earlier. Viable cell counts were determined by plating dilutions of the cell cultures onto TA plates. The rate of plasmid segregational loss was estimated by assaying the frequency of plasmid-free cells appearing after 14-16 hours of growth. Putative plasmid-free cells derived from JA122 and CV101 were identified using the iodometric assay of Boyko and Ganschow (1982) for $\beta$-lactamase. Putative plasmid-free cells derived from $\mathrm{CV} 103$ were identified by replica-plating colonies grown on TA plates, onto TA + tetracycline plates. Absence of a plasmid was confirmed by restreaking colonies and replica-plating onto TA + ampicillin + tetracycline plates. To verify the accuracy of this procedure, DNA preparations for a subsample of putative plasmidfree clones were resolved on agarose gels and asssayed for the presence of plasmid DNA using Southern hybridization as described above.

Estimates of the rate of segregational loss of the plasmid determined in this way are confounded with selective differences between plasmid-containing and plasmid-free strains (but see Noack et al., 1984; and Lenski and Bouma, 1987). However, this procedure allows relative changes in the rate of segregational loss to be identified, provided that the differences in the deleterious effects of the plasmids are not large.

\section{RESULTS}

A population, inoculated with a single clone of a plasmid-containing strain of $E$. coli was maintained in long-term glucose- 
TABLE 2. Reconstruction of changes.

\begin{tabular}{cccc}
\hline \hline Strain 1 & & Strain 2 & $\begin{array}{c}\text { Fitness of strain 2 } \\
\text { relative to a value } \\
\text { of 1 for strain 1 } 1 \pm \text { SE } \neq\end{array}$ \\
\hline CV101 $b_{1}+p_{1}$ & $\otimes$ & CV107 $b_{0}+p_{0}$ & $0.453 \pm 0.094 \dagger$ \\
CV103 $b_{2}+p_{2}$ & $\otimes$ & CV105 $b_{1}+p_{1}$ & $0.820 \pm 0.012 \dagger$ \\
CV103 $b_{2}+p_{2}$ & $\otimes$ & CV105 $b_{1}+p_{1}$ & $0.805 \pm 0.050 \dagger$ \\
CV103 $b_{2}+p_{2}$ & $\otimes$ & CV107 $b_{0}+p_{0}$ & $0.066 \pm 0.082 \dagger$ \\
\hline
\end{tabular}

$\dagger$ Fitnesses corrected for the effect of the arabinose marker.

$¥$ Standard error of the estimate.

limited continuous culture. At the termination of the experiment after approximately 773 generations, the population was shown to be polymorphic (Helling et al., 1987), with two majority and two minority types. The minority strains, designated CV101 and CV103, contained plasmids, which were shown on the basis of restriction mapping to be derived from the plasmid in the original strain used to inoculate the chemostat (JA122). A variety of physiological assays (Helling et al., 1987) indicated that all four strains were genetically different from each other and from the strain used to inoculate the chemostat (JA122).

Strains Isolated after Extensive Growth under Glucose Limitation Exhibit Higher Fitnesses in that Environment. - The physiological assays reported by Helling et al. (1987) suggest that the strains isolated after almost 800 generations of growth under glucose-limitation have adapted significantly to that environment. To confirm these increases in relative fitness, the strains were placed in direct competition with each other in the same glucose-limited environment, one of the strains being marked with resistance to arabinose. Table 2 shows the results of these experiments. The selective coefficients are corrected for the effect of the arabinose marker (see Materials and Methods). To aid in the interpretation of these and the other experiments described below, the bacterial chromosomes of JA122, CV101, and CV103 are denoted by $b_{0}, b_{1}$, and $b_{2}$, respectively, whereas the plasmid chromosomes of the same three strains are denoted as $p_{0}, p_{1}$, and $p_{2}$. The results indicate significant increases in the level of adaptation, with CV103 showing a significantly higher level of adaptation than CV101. Comparison of the pairwise relative fitness differences among the three strains does not in- dicate a simple additive or multiplicative relationshp between the fitness increments. Thus, the difference in fitness of JA122 and CV101 is 0.547 , and the difference in fitnesses of CV101 and CV103 is $0.18-0.195$. Yet, the difference in fitnesses between JA122 and CV103 is 0.943 , a value significantly larger than that expected if fitness effects were either additive or multiplicative, suggesting an interaction between the strains beyond a simple competition for a limiting nutrient.

Genetic adaptation to growth under glucose-limitation could have occurred as a result of one or more of the following: i) evolutionary changes in the bacterial chromosome; ii) evolutionary changes in the plasmid chromosome, resulting in a reduction of the deleterious effect associated with the presence of the plasmid; iii) coevolutionary changes in both the plasmid and the bacterial chromosomes, such that the interaction of the two resulted in fitness increases. To identify and distinguish among these three categories, strains were constructed carrying different combinations of bacterial and plasmid chromosomes, and competition experiments were carried out between them.

Adaptive Changes Occurring in the Bacterial Chromosome. - To identify adaptive changes that may have occurred in the bacterial chromosome, the two "evolved" strains, CV101 $\left(b_{1}+p_{1}\right)$, and CV103 $\left(b_{2}+\right.$ $p_{2}$ ) were cured of their plasmids, and placed in pairwise competition with themselves and with JA104, the plasmid-free strain used to construct JA122. Where necessary, one strain of each pair was marked with resistance to arabinose to distinguish them. Previous results had shown that this arabinose phenotype is weakly selected under our conditions (see Materials and Methods section) 
TABLE 3. Adaptation in the bacterial chromosome.

\begin{tabular}{|c|c|c|c|}
\hline Strain 1 & & Strain 2 & $\begin{array}{l}\text { Fitness of strain } 2 \\
\text { relative to a value } \\
\text { of } 1 \text { for strain } 1 \pm S E \ddagger\end{array}$ \\
\hline $\begin{array}{ll}\text { RIM21 } & b_{1} \\
\text { RIM21 } & b_{1}\end{array}$ & $\otimes$ & $\begin{array}{ll}\text { CV106 } & b_{0} \\
\text { CV106 } & b_{0}\end{array}$ & $\begin{array}{l}0.356 \pm 0.055 \dagger \\
0.454 \pm 0.066 \dagger\end{array}$ \\
\hline $\begin{array}{ll}\operatorname{RIM} 10 & b_{2} \\
\operatorname{RIM} 10 & b_{2} \\
\operatorname{RIM} 10 & b_{2}\end{array}$ & $\begin{array}{l}\otimes \\
\otimes \\
\otimes\end{array}$ & $\begin{array}{ll}\text { RIM21 } & b_{1} \\
\text { RIM21 } & b_{1} \\
\text { RIM21 } & b_{1}\end{array}$ & $\begin{array}{l}0.794 \pm 0.018 \\
0.878 \pm 0.026 \\
0.844 \pm 0.019\end{array}$ \\
\hline $\begin{array}{ll}\operatorname{RIM} 10 & b_{2} \\
\operatorname{RIM} 10 & b_{2}\end{array}$ & $\otimes$ & $\begin{array}{ll}\text { JA104 } & b_{0} \\
\text { JA104 } & b_{0}\end{array}$ & $\begin{array}{l}0.000 \pm 0.067 \\
0.178 \pm 0.094\end{array}$ \\
\hline
\end{tabular}

† Fitnesses corrected for the effect of the arabinose marker. ₹ Standard error of the estimate.

and the results of the experiments, shown in Table 3, were corrected where noted for the effect of this marker. As may be expected, the results show that dramatic genetic changes have occurred in the bacterial chromosomes of both CV101 and CV103 resulting in increases in fitness in both strains. For example, the fitness of strain JA104 $\left(b_{0}\right)$ is not significantly different from zero, relative to the fitness of the plasmidfree derivative $\left(b_{2}\right)$ of the second "evolved" strain.

Adaptation Reduces the Deleterious Effect of the Plasmid. - A multitude of studies has indicated that the presence of a wide variety of plasmids is generally deleterious to the growth of its bacterial host, though there are some notable exceptions (e.g., Wouters and van Andel, 1979; Bouma and Lenski, 1988). For pBR322 in particular, previous results (Jones et al., 1980; Wouters et al., 1980; Noack et al., 1981; Lee and Edlin, 1985) have shown a strong selective disadvantage associated with the presence of this plasmid. The first section of Table 4 shows a similar result for the plasmid (pBR322 $\Delta 5$ ), before long-term growth under glucose-limitation. The selective coefficient associated with this plasmid was $0.123-0.162$. It would thus be expected that evolutionary changes would tend to reduce the selective disadvantage associated with the plasmid, either through changes in the bacterial chromosome, or through changes in the plasmid chromosome, or both.

Table 4 shows the results of competition experiments between the original strain, the two evolved strains, and their corresponding plasmid-free derivatives. As expected the selective coefficients associated with the evolved plasmid $p_{2}$ are significantly smaller than those associated with the original plasmid $p_{0}(\alpha=0.05$; Mann-Whitney nonparametric test, e.g., Conover, 1971). The results shown in Table 4 do not permit us to draw any conclusion regarding the relative deleterious effect of the evolved plasmid $p_{1}$. Therefore, the comparative deleterious effects of the two plasmids $p_{0}$ and $p_{1}$ were determined directly from competition experiments between them in two different bacterial genomic backgrounds, $b_{0}$, and $b_{1}$. The results in Table 5 clearly show that plasmid $p_{0}$ is more deleterious than plasmid $p_{1}$, irrespective of the bacterial genomic background. The selective coefficients are not significantly different for the backgrounds $b_{0}$ and $b_{1}$, arguing that changes in the plasmid are mainly responsible for the reduction in the deleterious effect of the plasmid, and provide no evidence for an interaction, or coevolutionary changes between the the bacterial chromosome $b_{1}$ and the plasmid chromosome $p_{1}$.

Coevolutionary Changes in the Bacterial and Plasmid Chromosomes. - Table 6 shows the selective effect of the plasmid $p_{2}$ in two different bacterial genomic backgrounds $b_{0}$ and $b_{1}$, together with the results from Table 5 for comparison purposes. In these two

TABLE 4. Adaptation reduces the deleterious effect of the plasmid.

\begin{tabular}{cccc}
\hline Strain 1 & & Strain 2 & $\begin{array}{c}\text { Fitness of strain 2 relative to a value } \\
\text { of 1 for strain 1 } \pm \text { SE }\end{array}$ \\
\hline JA104 $b_{0}$ & $\otimes$ & JA122 $b_{0}+p_{0}$ & $0.838 \pm 0.039$ \\
JA104 $b_{0}$ & $\otimes$ & JA122 $b_{0}+p_{0}$ & $0.843 \pm 0.051$ \\
JA104 $b_{0}$ & $\otimes$ & JA122 $b_{0}+p_{0}$ & $0.877 \pm 0.025$ \\
RIM21 $b_{1}$ & $\otimes$ & CV105 $b_{1}+p_{1}$ & $0.900 \pm 0.021$ \\
RIM10 $b_{2}$ & $\otimes$ & CV103 $b_{2}+p_{2}$ & $0.926 \pm 0.021$ \\
RIM10 $b_{2}$ & $\otimes$ & CV103 $b_{2}+p_{2}$ & $0.887 \pm 0.047$ \\
RIM10 $b_{2}$ & $\otimes$ & CV103 $b_{2}+p_{2}$ & $0.944 \pm 0.024$ \\
\hline
\end{tabular}


TABLE 5. Analysis of the effect of the plasmid $p_{1}$.

\begin{tabular}{cclc}
\hline \hline Strain 1 & & \multicolumn{1}{c}{ Strain 2 } & $\begin{array}{c}\text { Fitness of strain } 2 \text { relative to a value } \\
\text { of } 1 \text { for strain 1 } \pm \text { SE } \neq\end{array}$ \\
\hline JA234 $b_{0}+p_{1}$ & $\otimes$ & CV107 $b_{0}+p_{0}$ & $0.965 \pm 0.006 \dagger$ \\
CV110 $b_{0}+p_{1}$ & $\otimes$ & JA122 $b_{0}+p_{0}$ & $0.895 \pm 0.022 \dagger$ \\
CV105 $b_{1}+p_{1}$ & $\otimes$ & RIM212 $b_{1}+p_{0}$ & $0.897 \pm 0.028 \dagger$ \\
CV105 $b_{1}+p_{1}$ & $\otimes$ & RIM212 $b_{1}+p_{0}$ & $0.917 \pm 0.007 \dagger$ \\
\hline
\end{tabular}

† Fitnesses corrected for the effect of the arabinose marker.

\$ Standard error of the estimate.

"foreign" backgrounds, the relative deleterious effects of the three plasmids can be ordered as

$$
p_{1}<p_{0}<p_{2}
$$

such that the plasmid $p_{2}$ is the most deleterious, and $p_{1}$ the least deleterious. The pattern of inequality is preserved in both genetic backgrounds, and contrasts with the results of Tables 4 and 5, which can be summarized in the same way as,

$$
p_{2} \leq p_{1}<p_{0} \text {. }
$$

Thus, the deleterious effect of plasmid $p_{2}$ is significantly less when assayed in the genomic background in which it has evolved, than in a "foreign" genomic background.

Plasmid Stability and Copy Number.Multi-copy plasmids generally are lost from cultures at low rates, due to the imperfect segregation of plasmids into the daughter cells at cell division (Summers and Sherratt, 1984). Consequently, stability of such plasmids would be expected to be influenced by copy number. Furthermore, under condi- tions where the plasmid has a negative effect on growth, it is reasonable to expect that a reduction in copy number would be accompanied by a reduction in the deleterious effect associated with the plasmid. Accordingly, plasmid copy number and the rate of segregation loss were measured for the original strain and the two evolved strains, CV101 $\left(b_{1}+p_{1}\right)$ and CV103 $\left(b_{2}+p_{2}\right)$. The results shown in Table 7 indicate that the rate of segregational loss has increased significantly in both"evolved" strains, and that the strain exhibiting the highest fitness in the chemostat, CV103 $\left(b_{2}+p_{2}\right)$ possesses a significantly higher segregation rate than the other "evolved" strain, CV101 $\left(b_{1}+\right.$ $\left.p_{1}\right)$. These estimates of segregation rate are biased upwards, due to selection against plasmid-containing cells, as detailed in the Materials and Methods section. However, the differences between JA122 $\left(b_{0}+p_{0}\right)$ and the "evolved" strains, and between the two evolved strains, CV101 $\left(b_{1}+p_{1}\right)$ and CV103 $\left(b_{2}+p_{2}\right)$, will be underestimated, because of the reduced deleterious effect of the plas-

TABLE 6. Analysis of the effect of the plasmid $p_{2}$ in different chromosome backgrounds.

\begin{tabular}{clll}
\hline Strain 1 & & \multicolumn{1}{c}{ Strain 2 } & $\begin{array}{c}\text { Fitness of strain 2 relative to a value } \\
\text { of } 1 \text { from strain 1 } \pm \text { SE }\end{array}$ \\
\hline In background $b_{0}$ & & & $1.206 \pm 0.090 \dagger$ \\
CV109 $b_{0}+p_{2}$ & $\otimes$ & JA122 $b_{0}+p_{0}$ & $1.550 \pm 0.058 \dagger$ \\
CV109 $b_{0}+p_{2}$ & $\otimes$ & JA234 $b_{0}+p_{1}$ & $1.360 \pm 0.044 \dagger$ \\
JA233 $b_{0}+p_{2}$ & CV110 $b_{0}+p_{1}$ & $0.965 \pm 0.006 \dagger$ \\
JA234 $b_{0}+p_{1}$ & $\otimes$ & CV107 $b_{0}+p_{0}$ & $0.895 \pm 0.022 \dagger$ \\
CV110 $b_{0}+p_{1}$ & $\otimes$ & JA122 $b_{0}+p_{0}$ & \\
In background $b_{1}$ & & & $1.198 \pm 0.026 \dagger$ \\
JA240 $b_{1}+p_{2}$ & $\otimes$ & RIM212 $b_{1}+p_{0}$ & $1.111 \pm 0.013 \dagger$ \\
RIM213 $b_{1}+p_{2}$ & $\otimes$ & JA238 $b_{1}+p_{0}$ & $1.088 \pm 0.016 \dagger$ \\
RIM213 $b_{1}+p_{2}$ & CV105 $b_{1}+p_{1}$ & $1.092 \pm 0.007 \dagger$ \\
RIM213 $b_{1}+p_{2}$ & CV105 $b_{1}+p_{1}$ & $0.897 \pm 0.025 \dagger$ \\
CV105 $b_{1}+p_{1}$ & $\otimes$ & RIM212 $b_{1}+p_{0}$ & $0.917 \pm 0.006 \dagger$ \\
CV105 $b_{1}+p_{1}$ & $\otimes$ & RIM212 $b_{1}+p_{0}$ & \\
\hline
\end{tabular}

+ Fitnesses corrected for the effect of the arabinose marker. 
TABLE 7. Rate of segregational loss of the plasmid. $\dagger$

\begin{tabular}{ccc}
\hline Strain & Designation & Segregation rate \pm SD $\ddagger$ \\
\hline JA122 & $b_{0}+p_{0}$ & $5.1 \times 10^{-4} \pm 0.8 \times 10^{-4}$ \\
CV101 & $b_{1}+p_{1}$ & $2.7 \times 10^{-2} \pm 0.9 \times 10^{-2}$ \\
CV103 & $b_{2}+p_{2}$ & $7.2 \times 10^{-2} \pm 1.2 \times 10^{-2}$ \\
\hline
\end{tabular}

$\dagger$ Per cell per cell division.

$¥$ Standard deviation.

mids. Thus, the increase in segregation rate, inferred from the data of Table 7 , is conservative.

Table 8 presents two independent estimates of plasmid copy number in the same three strains. Direct plasmid copy number estimates were obtained by quantitative DNA blot hybridization using "slot-blotting" while an indirect measure of copy number was obtained by estimating the minimum inhibitory concentration (M.I.C.'s) of ampicillin. Both sets of estimates are consistent and show that plasmid copy number is reduced significantly in CV103 $\left(b_{2}+p_{2}\right)$, but that there is no significant reduction in plasmid copy number in CV101 $\left(b_{1}+p_{1}\right)$. Comparison of the results in Tables 7 and 8 , however, suggests that the increase in segregation rates observed cannot completely be explained by a reduction in copy number; CV101, which exhibits a significantly higher segregation rate compared to JA122, does not show a corresponding reduction in copy number.

\section{DISCUSSION}

Evolution of a host-parasite relationship may result in adaptive changes in one or both of the component members. Thus, in the context of bacterial-plasmid association, five possible evolutionary responses (or combinations thereof) are possible.

1) Adaptive genetic changes in the bacterial chromosome that are independent of the presence of the plasmid.

2) Adaptive genetic changes in the bacterial chromosome that ameliorate the deleterious effect of the plasmid, but which may or may not be specific to a particular plasmid. Such changes have been reported by Bouma and Lenski (1988).

3) Adaptive genetic changes in the plasmid that do not result in an amelioration of the deleterious effect of the plasmid, but which render the plasmid competitively
TABle 8. Plasmid copy number.

\begin{tabular}{cccc}
\hline \hline Strain & Designation & $\begin{array}{c}\text { Copy number } \\
\pm \text { SEM }\end{array}$ & M.I.C. \pm SEM $\neq$ \\
\hline JA122 & $b_{0}+p_{0}$ & $152 \pm 17$ & $1.91 \pm 0.17$ \\
CV101 & $b_{1}+p_{1}$ & $160 \pm 17$ & $1.69 \pm 0.03$ \\
CV103 & $b_{2}+p_{2}$ & $40 \pm 7$ & $0.54 \pm 0.06$ \\
\hline
\end{tabular}

† Average value obtained from six different sample preparations from two separate experiments. Cells were grown in glucose-limited chemostat

culture at a dilution rate of $0.2 \mathrm{hr}^{-1}$.
$\ddagger$ Minimum Inhibitory Concentration of ampicillin $(\mathrm{mg} / \mathrm{ml})$. See MaF Minimum Inhibitory Concentration of ampicillin (mg/ml). See Ma-
terials and Methods for further details. M.I.C.'s are indirect estimates of terials and Methods for further details. M.I.C.'s are indirect estimates of
plasmid copy number. Each figure represents an average of six different experiments \pm the standard error of the mean.

superior in relation to other plasmids within the cell. Such changes would have evolutionary significance only for conjugative plasmids, or plasmids that are nonconjugative, but nevertheless able to be moblized by conjugative plasmids.

4) Adaptive genetic changes in the plasmid that result in a general (that is not necessarily specific to the particular host) amelioration of the deleterious effect of the plasmid. Godwin and Slater (1979) have described the attenuation of the deleterious effect of a plasmid that was apparently due to changes in the plasmid itself.

5) Adaptive genetic changes in both the bacterial chromosome and the plasmid, which are specific to each other.

This last category can be considered to be a coevolutionary response of the bacterial host and the plasmid parasite and presupposes that the changes in each component member will be dependent on, and will occur in response to, changes in the other. However, a broader definition of coevolution does not require that the adaptive responses in the two components are in any way specific, and may simply involve a combination of the second and fourth evolutionary responses listed above. For example, evolution towards attenuation of the effect of the parasite on the host may result in attenuation of the parasitic effect for all hosts, not only those in which the parasite evolved. These broad and narrow definitions of coevolution are analogous to the concepts of general and specific combining ability, used in plant breeding (e.g., Allard, 1960). Futuyma and Slatkin (1983) have proposed similar definitions of coevolution that focus on the process of adaptation rath- 
er than on the resulting adaptive phenotypes.

The results presented here provide examples of evolutionary changes in bacterialplasmid populations that include several of the responses listed above, and which can be termed coevolutionary in both the general and the restrictive sense. Long-term adaptation to a glucose-limited chemostat environment results in changes in both the bacterial and plasmid chromosomes. In one case, the bacterial and plasmid chromosomes have evolved so as to minimize the deleterious effects of the plasmid in the genomic environment in which it had evolved.

Under conditions where plasmid-carriage is deleterious to the cell, selection for an increased rate of reproduction in the presence of the plasmid is obviously an important evolutionary strategy (Levin and Lenski, 1983), and has been reported previously (Helling et al., 1981; Bouma and Lenski, 1988). Our results show a major increase in the fitness of the bacterial chromosome, either in the presence or the absence of a plasmid (response 2, listed above), as well as a reduction in the deleterious effect of the plasmid $p_{1}$ relative to the original plasmid $p_{0}$ (response 4 , listed above). Results from the competition experiments clearly show that changes in the plasmid have reduced the deleterious effect of the plasmid (Tables 4 and 5), and also implicate changes in the bacterial chromosome (Table 6).

Changes that result in an attenuation of the deleterious effect of the plasmid would also be expected and are predicted by theoretical models (Levin and Lenski, 1983). Mutations have been described in both the host chromosome and the plasmid, which result in changes in copy number (e.g., Scott, 1984; Kües and Stahl, 1989). A lower copy number may reduce the energy load placed on the cell for plasmid DNA replication, transcription and translation, as well as the level of plasmid-mediated interference (Helling et al., 1981). The data in Table 8 show that CV103 has a significantly lower copy number than the original strain, JA122, though there is no apparent reduction in copy number for CV101. It is significant in this regard that the values for plasmid copy number under continuous culture conditions (see Table 8) are extremely high. This observation is consistent with the results of others who have shown that copy number of ColE1 type plasmids (such as pBR322) can increase drastically under conditions where growth rate is decreased (Chao and Bremer, 1986a, 1986b; Taxis du Poet et al., 1987). A higher plasmid copy number should allow a proportionately greater opportunity for a reduction in the deleterious effect of the plasmid, by a reduction in copy number. A reduction in the copy number is consistent with the increases in the rate of segregational loss observed (Table 7). Since pBR322 does not possess a par or par-like locus, segregational loss is determined by random diffusion of plasmid copies into the daughter cells at cell division. Thus, a reduction in copy number will result in a higher rate of segregational loss (Summers and Sherratt, 1984). The results in Tables 7 and 8 do not, however, show a perfect correspondence between a reduction in copy number and an increase in the rate of segregational loss, and this may be explained by changes in the relative levels of circular plasmid oligomers. Thus, a plasmid that forms high levels of circular oligomers will be expected to have, ceteris paribus, a higher level of segregational loss relative to a plasmid that exists exclusively in the monomeric form, even though the physical copy number is identical (Summers and Sherratt, 1984). Copy number as measured by quantitative DNA-DNA hybridization estimates the number of physical copies of the plasmid present in the cell without regard to the organization of the plasmid DNA into circular oligomers. The levels of circular oligomeric forms have been shown to be determined by both genetic elements in both the host chromosome and the plasmid (James et al., 1983), and in this regard we have noted variations between JA122, CV101 and CV103 (Al-Qadi, Helling, and Adams, unpubl. data).

Specific interactions between the bacterial and plasmid chromosomes, reducing the deleterious effect of the plasmid, involve the bacterial chromosomes $b_{2}$ and the plasmid $p_{2}$, are shown in Table 6 and can be considered an example of coevolutionary changes in the narrow sense. From our knowledge of host and plasmid factors affecting copy number (e.g., Scott, 1984), it is 
not difficult to understand how interactions of this sort may occur. We believe that such interactions have been important factors in the evolution of associations between naturally occurring plasmids and their hosts.

\section{ACKNOWLEDGMENTS}

We thank F. Heffron for the gift of plasmid pBR322 $\Delta 5$, and R. A. Bender, D. Clewell, R. B. Helling, R. E. Lenski, J. Pringle, F. Rosenzweig, C. Wilke, and M. Zapp for helpful discussion. This work was supported in part by the National Institutes of Health grant GM30959.

\section{LtTerature Cited}

Adams, J., T. KinNey, S. Thompson, L. Rubin, AND R. B. Helling. 1979. Frequency-dependent selection for plasmid-containing cells of Escherichia coli. Genetics 91:627-637.

Allard, R. W. 1960 . Principles of Plant Breeding. Wiley and Sons, N.Y.

BOE, L., K. GERDES, AND S. MoLIN. 1987. Effects of genes exerting growth inhibition and plasmid stability on plasmid maintenance. J. Bacteriol. 169: 4646-4650.

Boyer, H., E. ENGlesberg, AND R. WeInberg. 1962. Direct selection of $L$-arabinose negative mutants of Escherichia coli strain B/r. Genetics 47:417-425.

BOUMA, J. E., AND R. E. LENSKI. 1988. Evolution of a bacteria/plasmid association. Nature 335:351-352.

BoYko, W. L., AND R. E. Ganschow. 1982. Rapid identification of Escherichia coli transformed by pBR322 carrying inserts at the PstI site. Anal. Biochem. 122:85-88.

Chao, L., AND H. Bremer. 1986a. Effect of the bacterial growth rate on replication control of plasmid pBR322 in Escherichia coli. Mol. Gen. Genet. 203: $143-149$.

CHAO, L., AND H. BREMER. 1986 b. Effect of relA function on the replication of plasmid pBR322 in Escherichia coli. Mol. Gen. Genet. 203:150-153.

ChIANG, C. S., AND H. Bremer. 1988. Stability of pBR322-derived plasmids. Plasmid 20:207-220.

ConOver, W. J. 1971. Practical Non-Parametric Statistics. John Wiley, N.Y.

Davis, B. D., AND E. S. Mingloli. 1950. Mutants of Escherichia coli requiring methionine or vitamin B12. J. Bacteriol. 60:17-28.

Dixon, W. J., L. Engelman, J. W. Frane, M. A. Hill, R. I. JENNRICH, AND J. D. TOPOREK. 1985. BMDP Statistical Software. Univ. California Press, Berkeley.

ENGBERG, B., AND K. NORDSTROM. 1975. Replication of R-factor R1 in Escherichia coli $\mathrm{K} 12$ at different growth rates. J. Bacteriol. 123:179-186.

FUTUYMA, D. J., AND M. SlATKIN. 1983. Introduction, pp. 1-13. In D. J. Futuyma and M. Slatkin (eds.), Coevolution. Sinauer Assoc. MA.

GodWIN, D., AND J. H. Slater. 1979. The influence of the growth environment on the stability of a drug resistance plasmid in Escherichia coli K12. J. Gen. Microbiol. 111:201-210.

Heffron, F., R. Kostriken, C. Morita, AND R. ParKER. 1981. Tn3 encodes a site-specific recombination system: Identification of essential sequences, genes, and the actual site of recombination. Cold Spring Harbor Symp. Quant. Biol. 45:259-268.

HellnNG, R. B., T. KInNeY, AND J. ADAMS. 1981. The maintenance of plasmid-containing organisms in populations of Escherichia coli. J. Gen. Microbiol. 123:309-318.

Helling, R. B., C. N. Vargas, and J. Adams. 1987. Evolution of Escherichia coli during growth in a constant environment. Genetics 116:349-358.

INSELBURG, J. 1978. ColE1 plasmid mutants affecting growth of an Escherichia coli recB recC $s b c B$ mutant. J. Bacteriol. 133:433-436.

JAMES, A. A., P. T. Morrison, AND R. Kolodner. 1983. Isolation of genetic elements that increase frequencies of plasmid recombinants. Nature 303 : 256-259.

Jones, I. M., S. B. Primrose, A. Robinson, ANd D. C. ELLwOOD. 1980. Maintenance of some ColE1-type plasmids in continuous culture. Mol. Gen. Genet. 180:579-584.

KuBITSCHEK, H. E. 1970. Introduction to Research with Continuous Cultures. Prentice-Hall, Englewood Cliffs, NJ.

KüES, U., AND U. STAHL. 1989. Replication of plasmids in gram-negative bacteria. Microbiol. Rev. 53:491-516.

LEE, S. W., AND G. EDLIN. 1985. Expression of tetracycline resistance in pBR322 derivatives reduces the reproductive fitness of plasmid-containing $E$. coli. Gene 39:173-180.

LENSKI, R. E., AND J. E. Bouma. 1987. Effects of segregation and selection on instability of plasmid pACYC184 in Escherichia coli B. J. Bacteriol. 169: 5314-5316.

LeVIN, B. R., AND R. E. LeNSKI. 1983. Coevolution in bacteria and their viruses and plasmids, pp. 99127. In D. J. Futuyma and M. Slatkin (eds.), Coevolution. Sinauer Assoc., MA.

Maniatis, T., E. F. FrITSCh, AND J. SAMBroOK. 1982. Molecular Cloning-A Laboratory Manual. Cold Spring Harbor Laboratories, Cold Spring Harbor, N.Y.

Melling, J., D. C. Ellwood, AND A. Robinson. 1977. Survival of R-factor carrying Escherichia coli in mixed cultures in the chemostat. FEMS Microbiol. Lett. 2:87-89.

NOACK, D., G. MülleR, AND M. RoTH. 1984. Mathematical modelling of genetic segregation kinetics obtained with chemostat cultures of procaryotic microorganisms. Zeit. Allg. Mikrobiol. 24:459-465.

NoACK, D., M. Roth, R. Guether, G. MülleR, K. UNDISZ, C. HofFMEIER, AND S. Gaspar. 1981. Maintenance and genetic stability of vector plasmids pBR322 and pBR325 in Escherichia coli K12 strains grown in a chemostat. Mol. Gen. Genet. 184:121-124.

Roth, M., G. Müller, AND D. NoACK. 1980. Loss of the multi-copy resistance plasmid pBR325 from Escherichia coli CY2354 pBR325 during continuous cultivation, pp. 143-146. In S. Mitsuhasi, L. Rosival, and V. Krcmery (eds.), Fourth Interna- 
tional Symposium on Antibiotic Resistance. Aviceneum Prague and Springer-Verlag, West Berlin.

Scotr, J. R. 1984. Regulation of plasmid replication. Microbiol. Rev. 48:1-23.

Summers, D. K., and D. J. Sherratt. 1984. Multimerization of high copy number plasmids causes instability: ColE 1 encodes a determinant essential for plasmid monomerization and stability. Cell 36: 1097-1103.

TAXis du PoEt, P., Y. ARCand, R. Bernier, JR., J.-N. Barbotin, AND D. ThOmas. 1987. Plasmid stability in immobilized and free recombinant $E$. coli JM105(pKK223-200): Importance of oxygen diffusion, growth rate, and plasmid copy number. Appl. Environ. Microbiol. 53:1548-1555.

Wouters, J. T. M., F. L. Driehuis, P. J. Polaczek,
M.-L. H. A. van Oppenraay, AND J. G. van ANDEL. 1980. Persistance of the pBR322 plasmid in Escherichia coli $\mathrm{K} 12$ grown in chemostat cultures. Antonie van Leeuwenhoek, J. Microbiol. Serol. 45: 353-362.

WoUters, J. T. M., AND J. G. VAN ANDEL. 1979. R-plasmid persistance in Escherichia coli grown in chemostat cultures. Antonie van Leeuwenhoek, J. Microbiol. Serol. 45:317-318.

Zund, P., AND G. LEBEK. 1980. Generation timeprolonging $R$ plasmids: Correlation between increases in the generation time of Escherichia coli caused by R-plasmids and their molecular size. Plasmid 3:65-69.

Corresponding Editor: R. E. Lenski 